\title{
Van yöresinde koyun klinik mastitis olgularından izole edilen bakteri türlerinin prevalansı ve antimikrobiyel duyarlılıkları
}

\author{
Mehmet Salih Sercan Gökhan1 (), Özgül Gülaydın² () \\ ${ }^{1}$ Van Yüzüncü Yıl Üniversitesi, Veteriner Fakültesi, Sağlık Bilimleri Enstitüsü, Mikrobiyoloji AD, Van, Türkiye \\ ${ }^{2}$ Van Yüzüncü Yıl Üniversitesi, Veteriner Fakültesi, Mikrobiyoloji AD, Van, Türkiye
}

Geliş Tarihi / Received: 21.02.2020, Kabul tarihi / Accepted: 21.05.2020

\begin{abstract}
Özet: Bu çalışmada, Van ve yöresinde koyunlarda mastitis olgularına neden olan bazı bakteriyel etkenlerin prevalansının ve antimikrobiyel duyarlııılarının belirlenmesi amaçlandı. İzole edilen etkenlerin tür düzeyinde identifikasyonu otomatize bakteri identifikasyon cihazı ile yapılırken antimikrobiyel duyarlılı̆ın belirlenmesinde disk difüzyon testi kullanıldı. Çalışmada 103 mastitisli süt örneğinin 51 (\%49,51)'inden bakteriyel etken izole edilirken, örneklerin geri kalanında bakteriyel üremenin olmadığı görüldü. Araştırmada en fazla izole edilen bakteriyel etkenlerin sırasıyla Pseudomonas spp. $(\% 27,1)$, Mannheimia haemolytica (\%16,94), Staphylococcus spp. $(\% 13,55)$ ve Streptococcus pneumoniae $(\% 11,86)$ olduğu belirlendi. Bununla birlikte Gram negatif bakteriyel etkenlerin sırasıyla \%72,2, \%52,8, \%42,2, $\% 25, \% 50$ ve \%50'sinin penisilin, sefoksitin, tetrasiklin, trimetoprim-sulfametaksazol, tilmikosin ve eritromisine dirençli olduğu belirlendi. Gram pozitif bakteriyel etkenlerin ise metisilin, sefoksitin, enrofloksasin, tilmikosin, eritromisin ve gentamisine sırasıyla \%21,7, \%43,4, \%8,7, \%8,7, \%8,7 ve \%4,3'ü dirençli bulundu. Sonuç olarak bu çalışmada koyunlarda mastitis olgularında Gram pozitif bakteriyel etkenlerin yanı sıra Pseudomonas spp. ve Mannheimia haemolytica izolatlarının da önemli rol oynayabileceği gözlendi. Bununla birlikte Van ve yöresinde koyunlarda mastitis vakalarının tedavisinde penisilin, sefoksitin, tetrasiklin, tilmikosin ve eritromisin kullanımına dikkat edilmesi gerektiği belirlendi.
\end{abstract}

Anahtar kelimeler: Antimikrobiyel duyarlılık, koyun, mastitis, prevalans

\section{Prevalance and antimicrobial susceptibility of bacterial species isolated from ovine clinical mastitis cases in Van province}

\begin{abstract}
The aim of this study was to determine the prevalence and antimicrobial susceptibility of some bacterial agents causing mastitis in sheep in Van province. Identification of isolated agents at species level was performed by automated bacteria identification system and disc diffusion test was used to determine the antimicrobial susceptibility. In the study, bacterial agent was isolated from 51 (49.51\%) of 103 milk samples, while no bacterial growth was in the rest of the samples. It was determined that Pseudomonas spp. (27.1\%), Mannheimia haemolytica (16.94\%), Staphylococcus spp. (13.55\%) and Streptococcus pneumoniae (11.86\%) were mostly isolated bacterial agents. In addition, $72.2 \%$, $52.8 \%, 42.2 \%, 25 \%, 50 \%$ and $50 \%$ of Gram negative bacterial agents were resistant to penicillin, cefoxitin, tetracycline, co-trimaxozole, tilmicosin and erythromycin, respectively. Also, $21.7 \%, 43.4 \%, 8.7 \%, 8.7 \%, 8.7 \%$ and $4.3 \%$ of Gram positive bacterial agents were resistant to methicillin, cefoxitin, enrofloxacin, tilmicosin, erythromycin and gentamicin, respectively. In conclusion, it was observed that Pseudomonas spp. and Mannheimia haemolytica isolates could play an important role in mastitis cases in sheep as well as Gram positive bacterial agents. Additionaly, it was determined that the use of penicillin, cefoxitin, tetracycline, tilmicosin and erythromycin should be considered in the treatment of mastitis in sheep in Van province.
\end{abstract}

Key words: Antimicrobial susceptibility, mastitis, prevalance, sheep

\section{Giriş}

Mastitis, meme dokusunda görülen yangısal reaksiyonlar ile sütün fiziksel ve kimyasal yapısındaki değişimlerle karakterize bir enfeksiyondur (Sasshofer ve ark. 1987). Grekçe meme anlamına gelen "mastos" ve yangı anlamına gelen "itis" kelimelerinden oluşmaktadır (Kesenkaş 1999; Yağcı 2008). Mastitisler, meme loblarında değiş̧en derecede klinik semptomların gözlendiği klinik mastitis ya da klinik semptom ve sütte fiziksel herhangi bir değişikliğin fark edil- mediği subklinik mastitis şeklinde seyredebilmektedir (Manser 1986; Contreras ve ark. 1999).

Mastitis, süt kalitesinde ve miktarında azalma ile birlikte antibiyotik kullanımına ve veteriner hekim hizmetlerine bağlı olarak artan maliyetler nedeniyle süt yönlü koyun yetiştiriciliğinde önemli ekonomik kayıplara sebep olmaktadır (Sabuncuoğlu ve Çoban 2006). Bununla birlikte mastitis olgularının sık görüldüğü sürülerde anaç koyunların kuzulara yeterince 
kolostrum sağlayamaması sonucunda kuzularda düşük canlı ağırlık gözlenmekte ve neonatal enfeksiyonların görülme oranı da artmaktadır (Mørk ve ark. 2007).

Mastitislerin tanısında kullanılan teşhis yöntemleri hastalığın seyrine göre değişmektedir (Yağcı 2008). Klinik mastitislerde memelerin ve sütün klinik, fiziksel ve bakteriyolojik muayenesi yapılırken özellikle subklinik mastitislerin teşhisinde somatik hücre sayımı, sütün elektriksel iletkenliğinin ölçülmesi ve sütteki enzimlerin ölçülmesi esasına dayalı olan biyokimyasal yöntemler kullanılmaktadır (Yağcı 2008; Gelasakis ve ark. 2015). Ancak hastalığın teşhisi ve etiyolojisinin belirlenmesinde mikrobiyolojik teşhis metotları altın standart olarak kabul edilmektedir (Fragkou ve ark. 2014; Gelasakis ve ark. 2015).

Yapılan çalışmalarda koyunlarda mastitise Staphylococcus spp., Streptococcus spp., Mannheimia spp., Enterobacteriaceae, Bacillus spp. ve Corynebacterium spp. gibi bakteriyel etkenlerin sebep olduğu bildirilmiştir (Gelasakis ve ark. 2015). Bununla birlikte Clostridium spp. (Mørk ve ark. 2007; Fotou ve ark. 2011), Enterococcus spp. (Marogna ve ark. 2010), Listeria monocytogenes (L. monocytogenes) (Winter ve ark. 2004; Brugère-Picoux 2008), Micrococcus spp. (Ariznabarreta ve ark. 2002), Mycobacterium spp. (Nebbia ve ark. 2006) ve Trueperella pyogenes (T. pyogenes) (Saratsis ve ark. 1998; Hadimli ve ark. 2010) gibi bakteriyel etkenlerin de mastitis olgularından izole ve identifiye edildiği bildirilmiştir.

Ülkemizde, sığırlardaki subklinik ve klinik mastitis olgularından çeşitli bakteriyel etkenlerin izolasyon ve identifikasyonu, antimikrobiyel duyarlııkları ve virülens faktörleri ile birlikte bazı fenotipik ve genotipik özelliklerinin araştııılığı çok sayıda çalışma bulunmaktadır (Gülcü ve Ertaş 2004; Tel ve ark. 2009; Türkyılmaz ve ark. 2010; Dinç ve ark. 2012; Gökdağ 2017; Kurt 2018; Özdemir 2018; Erdoğdu 2019; Sur 2019). Bazı araştırmacılar da keçilerde görülen mastitis vakalarında bakteriyel ve mikotik etkenlerin antimikrobiyel ve antimikotik ajanlara karşı duyarlııklarını belirlemişlerdir (İşnel Ceylan 2009; Uçan 2014; Koltaş 2016). Ancak koyunlarda özellikle klinik mastitis olgularına neden olan etkenlerin kapsamının ve antimikrobiyel duyarlıııklarının belirlendiği araştırmaya daha az oranda rastlanmıştır (Batu ve Fırat 1981; Baysal ve Kenar 1989; Erganiş ve ark. 1995).

Bu çalışmada ise Van yöresinde koyunlarda klinik mastitis vakalarından izole edilen bazı bakteriyel etkenlerin prevalansının ve antimikrobiyel duyarlılıklarının belirlenmesi amaçlandı.

\section{Gereç ve Yöntem}

\section{Gereç}

Bu çalışmada, Temmuz 2019-Eylül 2019 tarihleri arasında Van ili ve çevresinde yetiştiriciliği yapılan ve klinik olarak mastitis tanısı koyulan değişik ırk ve yaştaki koyunlardan alınan 103 adet mastitisli süt örneği kullanıldı. Örnekler, aseptik koşullarda steril tüplere alınarak soğuk zincirde laboratuvara getirildi. Çalışmada kullanılan mastitisli süt örnekleri Van iline bağlı 5 farklı ilçe ve bunlara bağlı 20 farklı köy ile 23 farklı çiftlikten toplandı (Tablo 1). Numunelerin toplanabilmesi için Van Yüzüncü Yıl Üniversitesi Hayvan Deneyleri Yerel Etik Kurulu'nun 2019/6 nolu kararı ile onay alındı.

Tablo 1. Çalışmada kullanılan mastitisli süt örneklerinin Van iline bağlı ilçe ve köylere göre dağılımı.

\begin{tabular}{cllc}
\hline Çiftlik No & illçe & Köy & Örnek Sayısı (n:103) \\
\hline 1 & Tuşba & Erçek & 2 \\
2 & Tuşba & Göllü & 8 \\
\hline 3 & Tuşba & Göllü & 2 \\
\hline 4 & Tuşba & Avirek & 4 \\
\hline 5 & Tuşba & Gedelova & 6 \\
\hline 6 & İpekyolu & Beşçatak & 5 \\
\hline 7 & İpekyolu & Güvelek & 4 \\
\hline 8 & Edremit & Kurubaş & 7 \\
\hline 9 & Gürpınar & Geçerli & 3 \\
\hline 10 & Gürpınar & Otbiçer & 11 \\
\hline 11 & Gürpınar & Otbiçer & 4 \\
\hline 12 & Gürpınar & Geziyurt & 2 \\
\hline 13 & Gürpınar & Günbaşı & 2 \\
\hline 14 & Gürpınar & Çörekli & 2 \\
\hline 15 & Gürpınar & Sevindik & 2 \\
\hline 16 & Gürpınar & Bolyanık & 8 \\
\hline 17 & Gürpınar & Cevizalan & 6 \\
\hline 18 & Gürpınar & Koçgüden & 5 \\
\hline 19 & Gürpınar & Koçgüden & 4 \\
\hline 20 & Gürpınar & Yoldüştü & 3 \\
\hline 21 & Gürpınar & Murataldı & 3 \\
\hline 22 & Başkale & Güvendi & 4 \\
\hline 23 & Başkale & Oğullu & 6 \\
\hline
\end{tabular}

\section{Bakteri izolasyon ve identifikasyonu}

Mastitisli süt örnekleri vorteks ile homojenize edildikten sonra öze ile \%5 defibrine koyun kanı katılmış kanlı agar besiyeri (Oxoid, CM0271, İngiltere), MacConkey Agar (Merck, 1.05465, Almanya), Mannitol Salt Agar (Oxoid, CM85, Ingiltere) ve Slanetz Bartley Medium (Oxoid, CM0377, Ingiltere) besiyerlerine ekim yapıldı. Besiyerleri $37^{\circ} \mathrm{C}$ 'de aerobik ortamda 24-48 saat inkübe edildi. İzolatlar, Gram 
boyama, morfolojik özellik, katalaz ve oksidaz reaksiyonları ile selektif besiyerinde üreme özelliklerine göre değerlendirildi (Quinn ve ark. 2011).

İzolatların tür düzeyinde identifikasyonları otomatize bakteri tanımlama cihazı (BD Phoenix, Amerika Birleşik Devletleri) ile yapıldı. Bu amaçla Gram pozitif olduğu belirlenen izolatların identifikasyonunda BD Phoenix ${ }^{\mathrm{TM}}$ PMIC / D-87 paneli; Gram negatifler için BD Phoenix ${ }^{\mathrm{TM}}$ NMIC / D-400 paneli kullanıldı. Testin yapılışı ve değerlendirilmesinde üretici firma önerileri dikkate alındı (Anonim 2006).

\section{Antimikrobiyel duyarlılığın belirlenmesi}

İolatların antimikrobiyel duyarlılıkları Bauer ve ark.'nın (1966) bildirdiği disk difüzyon yöntemi ile belirlendi. Antimikrobiyel duyarlılığın belirlenmesinde Gram pozitif bakteriyel etkenler için; penisilin $G$ ( $P, 10$ units, Oxoid), metisilin (MET, 10 mcg, Oxoid), sefoksitin (CX, 30 mcg, Himedia), vankomisin (VA, $30 \mathrm{mcg}$, Oxoid), tetrasiklin (TE, $30 \mathrm{mcg}$, Himedia), trimetoprim-sulfametaksazol (COT, 23.75/1.25 mcg, Himedia), eritromisin ( $\mathrm{E}, 15 \mathrm{mcg}$, Oxoid), tilmikosin (TIL, $15 \mathrm{mcg}$, Bioanalyse), enrofloksasin (ENR, $5 \mathrm{mcg}$, Oxoid) ve gentamisin (CN, 10 mcg, Oxoid); Gram negatif bakteriyel etkenler için ise penisilin $G$ ( $P, 10$ units, Oxoid), sefoksitin (CX, $30 \mathrm{mcg}$, Himedia), tetrasiklin (TE, 30 mcg, Himedia), trimetoprim-sulfametaksazol (COT, 23.75/1.25 mcg, Himedia), eritromisin (E, 15 mcg, Oxoid), tilmikosin (TIL, 15 mcg, Bioanalyse), enrofloksasin (ENR, $5 \mathrm{mcg}$, Oxoid) ve gentamisin (CN, $10 \mathrm{mcg}$, Oxoid) antibiyotik diskleri kullanıldı. Testin değerlendirilmesinde Clinical Laboratory Standards Institute ve European Commitee on Antimicrobial Susceptibility Testing kriterleri dikkate alındı (CLSI 2002, 2018; EUCAST 2019). Antimikrobiyel duyarlılık sonuçları duyarlı (S), orta duyarlı (I) ve dirençli (R) olarak değerlendirildi. Buna göre, en az üç farklı grupta sınıflandırılan antimikrobiyel maddelerden bir ya da daha fazlasına direnç tespit edilmesi çoklu antibiyotik direnci olarak kabul edildi (Magiorakos ve ark. 2012). Testin yapılışında kontrol olarak E. coli ATCC $^{\circledR} 25922$, S. aureus ATCC ${ }^{\circledR} 25923$ ve S. pneumoniae ATCC $^{\circledR} 49619$ referans suşları kullanıldı.

\section{Bulgular}

\section{İzolasyon ve identifikasyon}

Klinik olarak mastitis teşhisi koyulan koyunlardan alınan 103 adet süt örneğinin $51(\% 49,51)^{\prime}$ inde bakteriyel etken izole edilirken, $52(\% 50,48)$ örnekte ise üremenin olmadığı görüldü. Bakteriyel üremenin görüldüğü 51 örneğin 8 (\%15.68)'inde iki farklı etken izole edilerek toplam 59 adet izolat elde edildi.
Mastitisli süt örneklerinden izole edilen 59 adet bakteriyel etkenin 36 (\%61)'sının Gram negatif çomak, 23 (\%39)'ünün de Gram pozitif kok olduğu belirlendi.

Mastitisli 103 adet süt örneğinden $16(\% 15,53)$ Pseudomonas spp. (8 adet Pseudomonas oryzihabitans (P. oryzihabitans), 4 adet Pseudomonas putida $(P$. putida), 2 adet Pseudomonas fluorescens ( $P$. fluorescens), 1 adet Pseudomonas luteola (P. luteola) ve 1 adet Pseudomonas spp.), $10(\% 9,70)$ Mannheimia haemolytica (M. haemolytica), $4(\% 3,88)$ Citrobacter freundii (C. freundii), $2(\% 1,94)$ Klebsiella pneumoniae (K. pneumoniae), $2(\% 1,94)$ Archromobacter spp., $1(\% 0,97)$ Serratia plymuthica (S. plymuthica), 1 $(\% 0,97)$ Weeksella virosa $(W$. virosa), $7(\% 6,79)$ S. penumoniae, $4(\% 3,88)$ Staphylococcus simulans (S. simulans), 3 (\%2,91) Staphylococcus epidermidis (S. epidermidis), $1(\% 0,97)$ S. aureus, $4(\% 3,88)$ Aerococcus viridans $(A$. viridans), $2(\% 1,94)$ Enterococcus faecium (E. faecium) ve $2(\% 1,94)$ Enterococcus hirae (E. hirae) identifiye edildi (Tablo 2).

Yapılan değerlendirmede en fazla izole edilen Gram negatif bakteriyel etkenin Pseudomonas spp. $(\% 15,53)$ olduğu ve bunu M. haemolytica $(\% 9,70)$ izolatlarının izlediği gözlenirken; Gram pozitif koklar arasında en sık izole edilen etkenin Staphylococcus spp. $(\% 7,76)$ ve S. pneumoniae $(\% 6,79)$ olduğu belirlendi.

Tablo 2. Mastitisli süt örneklerinden izole edilen bakteriyel etkenlerin dağılımı.

\begin{tabular}{lcc}
\hline İzolat & $\mathbf{n}$ & \% \\
\hline Gram negatif & & \\
P. oryzihabitans & 8 & 7,76 \\
P. putida & 4 & 3,88 \\
P. fluorescens & 2 & 1,94 \\
P. luteola & 1 & 0,97 \\
Pseudomonas spp. & 1 & 0,97 \\
M. haemolytica & 10 & 9,70 \\
C. freundii & 4 & 3,88 \\
K. pneumoniae & 2 & 1,94 \\
Archromobacter spp. & 2 & 1,94 \\
S. plymuthica & 1 & 0,97 \\
W. virosa & 1 & 0,97 \\
Toplam & $\mathbf{3 6}$ & $\mathbf{3 4 , 9 5}$ \\
\hline Gram pozitif & & \\
S. pneumoniae & 7 & 6,79 \\
S. simulans & 4 & 3,88 \\
S. epidermidis & 3 & 2,91 \\
S. aureus & 1 & 0,97 \\
A. viridans & 4 & 3,88 \\
E. faecium & 2 & 1,94 \\
E. hirae & 2 & 1,94 \\
Toplam & $\mathbf{2 3}$ & $\mathbf{2 2 , 3 3}$ \\
\hline
\end{tabular}




\section{Antimikrobiyel duyarlılık}

Gram negatif izolatların tümü enrofloksasin ve gentamisine duyarlı, penisilin, sefoksitin, tetrasiklin, trimetoprim-sulfametaksazol, tilmikosin ve eritromisine ise izolatların sırasıyla \%72,2, \%52,8, \%42,2, $\% 25, \% 50$ ve \%50'si dirençli bulundu (Tablo 3). Gram pozitif izolatların ise tümü penisilin, vankomisin, tetrasiklin ve trimetoprim-sulfametaksazole duyarlı bulundu. İzolatların \%21,7, \%43,4, \%8,7, \%8,7, \%8,7 ve $\% 4,3$ 'ü sırasıyla metisilin, sefoksitin, enrofloksa- sin, tilmikosin, eritromisin ve gentamisine dirençli bulundu (Tablo 4).

Araştırmada Enterobacteriaceae ve non-Enterobacteriaceae izolatlarının tamamında; Pseudomonas spp., Enterococcus spp. ve Aerococcus spp. izolatlarının ise \%50'sinde çoklu antibiyotik direnci tespit edildi. İzolatlarda belirlenen çoklu antibiyotik direnç profili Tablo 5'de gösterildi. M. haemolytica, Staphylococcus spp. ve S. pneumoniae izolatlarında ise çoklu antibiyotik direnci tespit edilmedi.

Tablo 3. Gram negatif bakteriyel izolatların disk difüzyon test sonuçları dağılımı.

\begin{tabular}{|c|c|c|c|c|c|c|c|c|c|c|c|c|c|}
\hline \multirow[b]{2}{*}{$\begin{array}{l}\text { Etken } \\
\text { Madde }\end{array}$} & \multicolumn{3}{|c|}{$\begin{array}{c}\text { Pseudomonas spp. } \\
\text { (n:16) }\end{array}$} & \multicolumn{3}{|c|}{$\begin{array}{c}\text { M. haemolytica* } \\
(\mathrm{n}: 10)\end{array}$} & \multicolumn{3}{|c|}{$\begin{array}{c}\text { Enterobacteriaceae }^{* * *} \\
(\mathrm{n}: 7)\end{array}$} & \multicolumn{3}{|c|}{$\begin{array}{c}\text { Non-Enterobacteriaceae }{ }^{* \star \star \star} \\
(\mathrm{n}: 3)\end{array}$} & \multirow{2}{*}{$\begin{array}{c}\begin{array}{c}\text { Toplam } \\
\text { (n:36) }\end{array} \\
\mathbf{R} \\
\mathbf{n}(\%)\end{array}$} \\
\hline & $\begin{array}{c}\text { S } \\
\text { n (\%) }\end{array}$ & $\begin{array}{c}\text { I } \\
\text { n (\%) }\end{array}$ & $\begin{array}{c}R \\
\text { n (\%) } \\
\end{array}$ & $\begin{array}{c} \\
\text { n (\%) }\end{array}$ & $\begin{array}{c}\text { I } \\
\text { n (\%) }\end{array}$ & $\begin{array}{c}\text { R } \\
\text { n (\%) }\end{array}$ & $\begin{array}{c}\text { S } \\
\text { n (\%) }\end{array}$ & $\begin{array}{c}\text { I } \\
\text { n (\%) }\end{array}$ & $\begin{array}{c}R \\
\text { n (\%) }\end{array}$ & $\begin{array}{c}\text { S } \\
\text { n (\%) }\end{array}$ & $\begin{array}{c}\text { I } \\
\text { n (\%) }\end{array}$ & $\begin{array}{c}\text { R } \\
\text { n (\%) }\end{array}$ & \\
\hline$P$ & - & - & $16(100)$ & $10(100)$ & - & - & - & - & $7(100)$ & - & - & $3(100)$ & $26(72,2)$ \\
\hline$C X$ & - & - & $16(100)$ & $10(100)$ & - & - & $7(100)$ & - & - & - & - & $3(100)$ & $19(52,8)$ \\
\hline TE & $10(62,50)$ & - & $6(37,5)$ & - & - & $10(100)$ & $6(85,71)$ & $1(14,28)$ & - & $2(66,66)$ & - & $1(33,33)$ & $17(42,2)$ \\
\hline ENR & $15(93,75)$ & $1(6,25)$ & 0 & $10(100)$ & - & - & $7(100)$ & - & - & $3(100)$ & - & - & - \\
\hline СOT & $10(62,5)$ & - & $6(37,5)$ & $10(100)$ & - & - & $7(100)$ & - & - & - & - & $3(100)$ & $9(25)$ \\
\hline TIL & $8(50)$ & - & $8(50)$ & $10(100)$ & - & - & - & - & $7(100)$ & - & - & $3(100)$ & $18(50)$ \\
\hline$E$ & $8(50)$ & - & $8(50)$ & $3(30)$ & 7 (70) & - & - & - & $7(100)$ & - & - & $3(100)$ & $18(50)$ \\
\hline $\mathrm{CN}$ & $16(100)$ & - & - & $10(100)$ & - & - & $7(100)$ & - & - & $3(100)$ & - & - & - \\
\hline
\end{tabular}

P: Penisilin, CX: Sefoksitin, TE: Tetrasiklin, ENR: Enrofloksasin, COT: Trimetoprim-Sulfametaksazol, TIL: Tilmicosin, E: Eritromisin, CN: Gentamisin *: P, CX, TE ve COT için EUCAST (2019) P. multocida değerlendirme kriteri, TIL için CLSI (2018) P. multocida değerlendirme kriteri, E için CLSI (2002) P. multocida değerlendirme kriteri, ENR ve CN için ise CLSI (2018) P. aeruginosa değerlendirme kriterleri dikkate alındı. **: P, CX, TE, ENR ve COT için EUCAST (2019) P. multocida değerlendirme kriteri, TIL için CLSI (2018) değerlendirme kriteri, E ve CN için CLSI (2002) değerlendirme kriterleri dikkate alındı.

***: P, TIL ve E için CLSI (2002), CX için EUCAST (2019), TE, ENR, COT ve CN için CLSI (2018) değerlendirme kriterleri dikkate alındı. ****: Pseudomonas spp. için kullanılan değerlendirme kriterleri dikkate alındı.

Tablo 4. Gram pozitif bakteriyel izolatların disk difüzyon test sonuçları dağılımı.

\begin{tabular}{|c|c|c|c|c|c|c|c|c|c|c|c|c|c|}
\hline \multirow[b]{2}{*}{$\begin{array}{l}\text { Etken } \\
\text { Madde }\end{array}$} & \multicolumn{3}{|c|}{$\begin{array}{l}\text { S. pneumoniae } \\
(\mathrm{n}: 7)\end{array}$} & \multicolumn{3}{|c|}{$\begin{array}{l}\text { Staphylococcus spp. } \\
\text { (n:8) }\end{array}$} & \multicolumn{3}{|c|}{$\begin{array}{c}\text { Enterococcus spp. }{ }^{* * *} \\
(\mathrm{n}: 4)\end{array}$} & \multicolumn{3}{|c|}{$\begin{array}{l}\text { A. } \text { viridans }^{* \star n *} \\
(\mathrm{n}: 4)\end{array}$} & \multirow{2}{*}{$\begin{array}{c}\begin{array}{c}\text { Toplam } \\
\text { (n:23) }\end{array} \\
\begin{array}{c}R \\
n\end{array} \\
\end{array}$} \\
\hline & $\begin{array}{c}\text { S } \\
n(\%)\end{array}$ & $\begin{array}{c}\text { I } \\
\text { n (\%) }\end{array}$ & $\begin{array}{c}\mathbf{R} \\
\mathrm{n}(\%)\end{array}$ & $\begin{array}{c}\text { S } \\
\text { n (\%) }\end{array}$ & $\begin{array}{c}\text { I } \\
\text { n (\%) }\end{array}$ & $\begin{array}{c}\text { R } \\
\text { n (\%) }\end{array}$ & $\begin{array}{c}S \\
n(\%)\end{array}$ & $\begin{array}{c}\text { I } \\
\text { n (\%) }\end{array}$ & $\begin{array}{c}\text { R } \\
\text { n (\%) }\end{array}$ & $\begin{array}{c}S \\
n(\%)\end{array}$ & $\begin{array}{c}\text { I } \\
\text { n (\%) }\end{array}$ & $\begin{array}{c}\text { R } \\
\text { n (\%) }\end{array}$ & \\
\hline$P$ & $7(100)$ & - & - & $8(100)$ & - & - & $4(100)$ & - & - & $4(100)$ & - & - & - \\
\hline MET & $7(100)$ & - & - & $8(100)$ & - & - & - & - & $4(100)$ & $3(75)$ & - & $1(25)$ & $5(21,7)$ \\
\hline VA & $7(100)$ & - & - & $8(100)$ & - & - & $4(100)$ & - & - & $4(100)$ & - & - & - \\
\hline$C X$ & $5(71,42)$ & - & $2(28,57)$ & $8(100)$ & - & - & - & - & $4(100)$ & - & - & $4(100)$ & $10(43,4)$ \\
\hline TE & $5(71,42)$ & $2(28,57)$ & - & $8(100)$ & - & - & $4(100)$ & - & - & $4(100)$ & - & - & - \\
\hline ENR & $3(42,85)$ & $4(57,14)$ & - & $8(100)$ & - & - & - & $2(50)$ & $2(50)$ & - & $4(100)$ & - & $2(8,7)$ \\
\hline СОT & $7(100)$ & - & - & $8(100)$ & - & - & $4(100)$ & - & - & $4(100)$ & - & - & - \\
\hline TIL & $5(71,42)$ & $2(2,57)$ & - & $6(75)$ & $2(25)$ & - & - & $4(100)$ & - & - & $2(50)$ & $2(50)$ & $2(8,7)$ \\
\hline $\mathrm{E}$ & $7(100)$ & - & - & $8(100)$ & - & - & $1(25)$ & $3(75)$ & - & $2(50)$ & - & $2(50)$ & $2(8,7)$ \\
\hline $\mathrm{CN}$ & $7(100)$ & - & - & $8(100)$ & - & - & $4(100)$ & - & - & $3(75)$ & - & $1(25)$ & $1(4,3)$ \\
\hline
\end{tabular}

P:Penisilin, CX: Sefoksitin, TE: Tetrasiklin, ENR: Enrofloksasin, COT: Trimetoprim-Sulfametaksazol, TIL: Tilmikosin, E: Eritromisin, CN: Gentamisin ": P, MET, ve COT için CLSI (2002), VA, TE, ENR, TIL ve E için CLSI (2018), CX ve CN için CLSI (2018) Staphylococcus spp. değerlendirme kriterleri dikkate alındı.

**: P, MET, CX, TE, ENR, COT, TIL, E ve CN için CLSI (2018), VA için CLSI (2002) değerlendirme kriterleri dikkate alındı.

${ }^{* * *}:$ P, TE, TIL ve E için CLSI (2018), MET, VA, CX ve ENR için CLSI (2018) Staphylococcus spp., COT için EUCAST (2019) ve CN için CLSI (2002)'de bildirilen dğerlendirme kriterleri dikkate alındı.

****: P ve VA için EUCAST (2019), CN için CLSI (2002), MET, CX, TE, ENR, COT, TIL ve E için Enterococcus spp. için kullanılan değerlendirme kriterleri dikkate alındı. 
Tablo 5. İzole edilen bakterilerin çoklu antibiyotik direnç profilleri.

\begin{tabular}{lll}
\hline İolat & $\mathbf{n}(\%)$ & Antibiyotikler \\
\hline & $5(31,25)$ & $\mathrm{P}, \mathrm{CX}, \mathrm{TE}, \mathrm{COT}, \mathrm{TIL}, \mathrm{E}$ \\
& $1(6,25)$ & $\mathrm{P}, \mathrm{CX}, \mathrm{TE}, \mathrm{TIL}, \mathrm{E}$ \\
Pseudomonas spp. & $1(6,25)$ & $\mathrm{P}, \mathrm{CX}, \mathrm{TiL}, \mathrm{E}$ \\
& $1(6,25)$ & $\mathrm{P}, \mathrm{CX}, \mathrm{COT}, \mathrm{TIL}, \mathrm{E}$ \\
\hline Enterobacteriaceae & $7(100)$ & $\mathrm{P}, \mathrm{TIL}, \mathrm{E}$ \\
\hline \multirow{2}{*}{ Non- Enterobacteriaceae } & $2(66,66)$ & $\mathrm{P}, \mathrm{CX}, \mathrm{COT}, \mathrm{TiL}, \mathrm{E}$ \\
& $1(33,33)$ & $\mathrm{P}, \mathrm{CX}, \mathrm{TE}, \mathrm{COT}, \mathrm{TIL}, \mathrm{E}$ \\
\hline Enterococcus spp. & $2(50)$ & $\mathrm{MET}, \mathrm{CX}, \mathrm{ENR}$ \\
Aerococcus spp. & $1(25)$ & $\mathrm{MET}, \mathrm{CX}, \mathrm{TiL}, \mathrm{E}$ \\
& $1(25)$ & $\mathrm{CX}, \mathrm{TIL}, \mathrm{E}, \mathrm{CN}$ \\
\hline
\end{tabular}

P:Penisilin, CX: Sefoksitin, TE: Tetrasiklin, ENR: Enrofloksasin, COT: Trimetoprim-Sulfametaksazol, TIL: Tilmikosin, E: Eritromisin, $\mathrm{CN}$ : Gentamisin

\section{Tartışma ve Sonuç}

Koyunlarda mastitis olguları, süt kalitesi ile veriminde azalmaya ve beslenme problemleri nedeniyle canlı kuzu ağırlığında düşüşe neden olarak hem süt hem de et yönlü yetiştiricilik yapılan sürülerde önemli ekonomik kayıplara yol açmaktadır (Mørk ve ark. 2007; Gelasakis ve ark. 2015). Klinik mastitis, koyunlarda huzursuzluk, depresyon, yem tüketiminde azalma, ağrı ve ateş gibi klinik semptomlara neden olarak hayvan refahını da olumsuz yönde etkilemektedir. Subklinik mastitis olgularında ise sütte makroskopik olarak bir değişim gözlenmemesine rağmen klinik mastitislere benzer şekilde hayvan refahı ve davranışları olumsuz yönde etkilenmektedir (Fthenakis ve Jones, 1990; Yağ cl, 2008). Koyunlarda klinik mastitislerin görülme sıklığının \%5 civarında olduğu bilinmekle birlikte subklinik mastitis vakalarının sürülerde oldukça yüksek (\%50) oranlarda seyredebildiği bildirilmiştir (Contreras ve ark. 2007).

Hayvan sayısı ve süt veriminin fazla olması nedeniyle sığırlarda görülen mastitis olgularıyla ile ilgili daha fazla çalışmaya rastlanmaktadır (Gülcü ve Ertaş 2004; Tel ve ark. 2009; Türkyılmaz ve ark. 2010; Aslantaş ve ark. 2011; Büyükcangaz ve ark. 2012; Dinç ve ark. 2012; Li ve ark. 2015; Bahramina ve ark. 2017; Dan ve ark. 2019). Ancak son zamanlarda koyun popülasyonundaki ve yetiştiriciliğindeki artış ile birlikte koyunlarda da mastitis olgularıyla ilgili yapılan çalışmaların sayısı hem ulusal hem de uluslararası alanda artış göstermektedir (Gelasakis ve ark. 2015).

Ülkemizde koyun ve keçilerde görülen mastitis olgularının ele alındığı çeşitli lisansüstü tez çalışmaları ve bireysel araştırmalar bulunmaktadır (Batu ve Fırat 1981; Baysal ve Kenar 1989; Erganiş ve ark 1995; İşnel Ceylan 2009; Uçan 2014; Koltaş 2016). Ancak yakın zamanda Van ve yöresinde koyunlarda klinik mastitise neden olan bakteriyel etkenlerin sıklığının ve antimikrobiyel duyarlıığının araştırıldığı çalışmaya rastlanmamıştır. Bu çalışmada Van ve yöresinde koyunlarda görülen klinik mastitis olgularından izole edilen bakteriyel etkenlerin prevalansı ve antimikrobiyel duyarlılıkları araştırıldı.

Birçok bakteriyel etken koyunlarda klinik ve subklinik mastitis olgularına neden olmaktadır ve bu etkenlerin teşhisinde genel olarak konvansiyonel bakteriyolojik yöntemlerden yararlanılmaktadır (Contreras ve ark. 2007; Olechnowicz ve Jaśkowski 2014; Gelasakis ve ark. 2015). Bununla birlikte mastitis etiyolojisinde yetiştiricilik yönünün önemli bir faktör olduğu, süt yönlü yetiştiricilik yapılan sürülerde S. aureus ve diğer Staphylococcus spp. izolatlarının (Bergoiner ve ark. 2003; Contreras ve ark. 2007; Mørk ve ark. 2007), et yönlü yetiştiricilik yapılan sürülerde ise daha çok $M$. haemolytica ve $S$. aureus izolatlarının mastitis vakalarından sorumlu olduğu belirlenmiştir (Gelasakis ve ark. 2015). Koyunlarda mastitis olgularının etiyolojisinin tespitine yönelik çalışmalarda $M$. haemolytica prevalansı oldukça yüksek (\%48-65) bulunsa da (Koop ve ark. 2010; Omaleki ve ark. 2010) bazı araştırmacılar bu oranın \%1-26 arasında sınırlı kaldığını bildirmişlerdir (Gülcü ve Öngör 2002; Mavrogianni ve ark. 2007; Arsenault ve ark. 2008). Sunulan bu çalışmada ise M. haemolytica prevalansının $\% 9,70$ olduğu tespit edildi ve bu durumun mastitisli süt örneklerinin daha çok süt yönlü yetiştiricilik yapılan sürülerden toplanması ile ilişkili olabileceği düşünüldü.

Staphylococcus spp. izolatları koyun mastitislerinde en sık teşhis edilen etkenlerdir (Olechnowicz ve Jaśkowski 2014). Özellikle S. aureus suşları hem sporadik mastitis olgularından hem de sürülerde salgın şeklinde seyreden vakalardan sorumlu tutulmaktadır (Bergonier ve ark. 2003). Birçok araştırmaCı koyun mastitislerinde \%13-80 arasında değişen oranlarda S. aureus izole ve identifiye ettiklerini bildirmişlerdir (Batu ve Fırat 1981; Erganiş ve ark. 1995; Jones ve Watkins 1998; Gülcü ve Öngör 2002; Mørk ve ark. 2007; Koop ve ark. 2010; Mavrogianni ve ark. 2011; Dore ve ark. 2016; Abdulhamed ve ark. 2018). Bununla birlikte koagülaz negatif Staphylococcus türleri de koyunlarda hem klinik hem de subklinik mastitis olgularında önemli rol oynamaktadır ve bu türler içinde S. epidermidis, S. simulans ve S. chromogenes izolatları daha yüksek oranda identifiye edilmektedir. Yapılan çalışmalarda koyunlarda mastitis olgularından koagülaz negatif Staphylococcus türlerinin 
izolasyon oranının da oldukça yüksek (\%40-70) bulunduğu belirtilmiştir (Erganiş ve ark. 1995; Dore ve ark. 2016; Ceniti ve ark. 2017; Queiroga 2017). Bazı araştırmacılar ise bu oranı daha düşük olarak belirlemişlerdir (Gülcü ve Öngör 2002; Onnosch ve ark. 2002; Dore ve ark. 2016). Sunulan bu çalışmada mastitisli süt örneklerinden $\% 0,97$ oranında S. aureus izole edilirken, koagülaz negatif türlerin (S. simulans ve S. epidermidis) izolasyon oranının \%3 olduğu ve elde edilen verilerin daha önce yapılan çalışmalara göre oldukça düşük bulunduğu gözlendi.

Streptococcus spp. izolatlarının genel olarak çiftlikteki hijyen eksikliklerine bağlı olarak sporadik mastitis vakalarına neden olduğu bilinmektedir (Zdragos ve ark. 2005; Contreras ve Rodriguez 2011). Koyun mastitislerinde Streptococcus spp. prevalansını Dore ve ark. (2016) \%3,6, Ceniti ve ark. (2017) \%7,95, Queiroga (2017) \%14,3, Abdulhamed ve ark. (2018) \%5,6 olarak bildirmişlerdir. Bu çalışmada ise diğer çalışmalara benzer şekilde süt örneklerinin \%6,79'unda S. pneumoniae identifiye edildi. Ancak; İtalya ve Almanya'da yapılan çalışmalarda Streptococcus türlerinin mastitisli koyun sütlerinden daha yüksek (\%23-31) oranda izole edildiği rapor edilmiştir (Marogna ve ark. 2010; Cuccuru ve ark. 2011; Kern ve ark. 2013).

Citrobacter spp., Klebsiella spp., Serratia spp., $P$. aeruginosa vb. Gram negatif etkenler de koyun sütlerinden izole ve identifiye edilebilmekle birlikte bu etkenler hayvanın immun sistem yanıtına göre klinik mastitislere neden olabilen çevresel etkenler olarak kabul edilmektedir (Contreras ve Rodríguez, 2011). Dore ve ark. (2016) yaptıkları çalışmada \%3,8 oranında Enterobacteriacea, \%4,3 oranında Pseudomonas spp., Abdulhamed ve ark. (2018) \%3,77 oranında Klebsiella spp., \%1,89 oranında Pseudomonas spp., Queiroga (2017) ise \%3,6 oranında P. aeruginosa izole ettiklerini bildirmişlerdir. Bu araştırmada ise yapılan çalışmalardan farklı olarak Pseudomonas spp. izolatlarının prevalansı \%15,53 olarak tespit edildi. Enterobacteriacea izolatları ise diğer çalışmalara benzer şekilde mastitisli süt örneklerinin \%1-3'ünden izole edildi. Van ve yöresinde özellikle yaz aylarında koyun sürülerinin daha çok yüksek meralarda otlatılması ve meme uçlarının çevrede ve toprakta bol bulunabilen Pseudomonas spp. etkenleri ile olası kontaminasyonunun mastitise neden olmuş olabileceği düşünüldü.

Koyunlarda meme enfeksiyonlarının kontrol ve tedavisinde kuru dönem terapisinin önem arz ettiği vurgulanmaktadır (Fthenakis ve ark. 2012). Ancak etkin tedavi protokolü ile ilgili detaylı bilgi bulunmamakla birlikte spesifik olarak koyun mastitisleri- ne yönelik sınırlı sayıda kemoteröpatik madde bulunmaktadır (Gelasakis ve ark. 2015). Özellikle son yıllarda bilinçsiz antibiyotik kullanımına bağlı olarak insan tüketimine sunulan hayvansal gıdalarda antibiyotik kalıntısının bulunması ve dirençli bakteri sayısındaki artış, mastitis olgularında mikrobiyolojik teşhis ve antimikrobiyel duyarlılık testlerinin önemini arttırmaktadır (Petridis ve Fthenakis 2014). Bu kapsamda koyunlarda mastitis etiyolojisine yönelik daha fazla çalışma olmasına rağmen, izolatlarda antimikrobiyel duyarlılığın belirlendiği sınırlı sayıda araştırma bulunmakta ve konu ile ilgili çalışmaların daha çok Staphylocccus spp. izolatlarına yönelik olduğu görülmektedir (Fthenakis 1998; Lollai ve ark. 2008; Onni ve ark. 2011; Azara ve ark. 2017; Obaidat ve ark. 2018).

Koyunlarda mastitis olgularından izole edilen S. aureus, Staphylococcus spp. ve Streptococcus spp. izolatlarının antimikrobiyel duyarlılığının belirlendiği çalışmalarda penisilin dirençli suş sayısının genel olarak düşük olduğu bildirilirken (Lollai ve ark. 2008; Azara ve ark. 2017; Ceniti ve ark. 2017) bazı araştırmacılar ise Staphylococcus türlerinde penisilin dirençli izolat sayısının \%65'e ulaşabildiğini rapor etmişlerdir (Fthenakis 1998; Onni ve ark. 2011; Abdulhamed ve ark. 2018). Araştırmalarda metisilin dirençli Staphylococcus spp. prevalansının koyun mastitislerinde oldukça düşük (\%1) olduğu ancak, tetrasiklin, trimetoprim-sulfametoksazol, eritromisin ve gentamisine dirençli Gram pozitif izolat sayısının farklılık gösterdiği belirlenmiştir (Fthenakis 1998; Onni ve ark. 2011; Azara ve ark. 2017; Ceniti ve ark. 2017; Abdulhamed ve ark. 2018; Obaidat ve ark. 2018). Benzer şekilde sunulan bu çalışmada da elde edilen Gram pozitif izolatlarda antimikrobiyel dirençli suş sayısının düşük olduğu görüldü. Staphylococcus spp. izolatlarında metisilin dirençli suşlara rastlanmazken, penisilinin Gram pozitif etkenler üzerinde etkili olduğu belirlendi. Bununla birlikte etkenlerin büyük çoğunluğu tetrasiklin, trimetoprim-sulfametoksazol, eritromisin ve gentamisine duyarlı bulundu. Gram negatif bakteriyel etkenlerin penisilin, sefoksitin, tetrasiklin, tilmikosin ve eritromisine sırasıyla $\% 72,2, \% 52,8, \% 42,2, \% 50$ ve $\% 50$ 'sinin dirençli olduğu tespit edilirken, gentamisinin Gram negatif etkenlerin neden olduğu mastitis olgularında etkili olabileceği görüldü. Gentamisin ile ilgili elde edilen verilerin Abdulhamed ve ark. (2018) tarafından rapor edilen bulgular ile uyumlu olduğu belirlendi.

Sonuç olarak bu çalışmada Van ve yöresinde koyunlarda mastitis olgularında Gram pozitif bakteriyel etkenler ile birlikte Gram negatif bakteriyel 
etkenlerin de önemli rol oynayabileceği gözlendi. Özellikle Pseudomonas spp. ve M. haemolytica suşlarının koyun klinik mastitislerinde göz önünde bulundurulması ve Van yöresinde koyunlarda mastitis vakalarının tedavisinde penisilin, sefoksitin, tetrasiklin, tilmikosin ve eritromisin kullanımına dikkat edilmesi gerektiği belirlendi. Çalışmadan elde edilen verilerin bölgede küçükbaş hayvanlarda görülen mastitis vakalarının etiyolojisi, etkin tedavi stratejilerinin belirlenmesi ve hastalığın kontrolüne ilişkin çalışmalara önemli katkı sağlayacağı düşünüldü.

Deney hayvanları kullanımı etik kurulu ve diğer etik kurul kararları ve izinler: Bu çalışma, Van Yüzüncü Yıl Üniversitesi Hayvan Deneyleri Yerel Etik Kurulu'nun 2019/6 nolu kararı ile onaylanmıştır.

Teşekkür: Bu çalışma, ilk yazarın aynı başlıklı yüksek lisans tezinden özetlenmiştir.

Maddi destek ve çıkar ilişkisi: Bu çalışma, Van Yüzüncü Yıl Üniversitesi Bilimsel Araştırma Projeleri Koordinasyon Birimi tarafından TYL-2019-8493 nolu proje olarak desteklenmiştir.

\section{Kaynaklar}

1- Abdalhamed AM, Zeedan GSG, Zeina HAAA. (2018) Isolation and identification of bacteria causing mastitis in small ruminants and their susceptibility to antibiotics, honey, essential oils, and plant extracts. Vet World. 11(3), 355-362.

2- Anonim. (2006) BD Phoenix System user's manuel. Maryland: Becton, Dickinson and Company.

3- Ariznabarreta A, Gonzalo C, San Primitivo F. (2002) Microbiological quality and somatic cell count of ewe milk with special reference to Staphylococci. J Dairy Sci. 85, 1370-1375.

4- Arsenault J, Dubreuil P, Higgins R, Belanger D. (2008) Risk factors and impacts of clinical and subclinical mastitis in commercial meat producing sheep flocks in Quebec, Canada. Prev Vet Med. 87, 373-393.

5- Aslantaş Ö, Öztürk F, Ceylan A. (2011) Prevalence and molecular mechanism of macrolide and lincosamide resistance in Staphylococci isolated from subclinical bovine mastitis in Turkey. J Vet Med Sci. 73(12), 1645-1648.

6- Azara E, Piras MG, Parisi A, Tola S. (2017) Antimicrobial susceptibility and genotyping of Staphylococcus aureus isolates collected between 1986 and 2015 from ovine mastitis. Vet Microbiol. 205, 53-56.

7- Bahraminia F, Emadi SR, Emaneini M, Farzaneh $N$, Rad M, Khoramian B. (2017) A high prevalence of tylosin resistance among Staphylococcus aureus strains isolated from bovine mastitis. Vet Res Forum. 8(2), 121-125.

8- Batu A, Firat G. (1981) Trakya ve Marmara bölgesinde koyunlarda klinik ve subklinik mastitisler ve etkenleri üzerinde araştırma. Pendik Vet Mikrobiyol Derg. 13(1), 11-21.

9- Bauer AW, Kirby WMM, Sherris JC, Turck M. (1966) Antibiotic susceptibility testing by a standardized single disc method. Am J Clin Pathol. 45, 493-494.

10- Baysal T, Kenar B. (1989) Konya ve yöresindeki koyunlarda klinik ve subklinik mastitis olgularından aerob etken izolasyon ve identifikasyonu. Etlik Vet Mikrobiyol Derg. 6(4), 55-66.

11- Bergonier $D$, Crémoux RD, Rupp R, Lagriffoul G, Berthelot $X$. (2003) Mastitis of dairy small ruminants. Vet Res. 34, 689-716.
12- Brugère-Picoux J. (2008) Ovine listeriosis. Small Ruminant Res. $76,12-20$

13- Büyükcangaz E, Mat B, Khider Abd Alrahim Ahmed M. (2012) Subklinik mastitisli sığır sütlerinin mikrobiyolojik analizi ve izolatların antimikrobiyal direnç profili. Uludag Univ J Fac Vet Med. 31(2), 35-44.

14- Ceniti C, Britti D, Santoro AML, Musarella R, Ciambrone L, Casalinuovo F, Costanzo N. (2017) Phenotypic antimicrobial resistance profile of isolates causing clinical mastitis in dairy animals. IJFS. 6, 84-87.

15- CLSI. (2002) Performance standards for antimicrobial disk and dilution susceptibility tests for bacteria isolated from animals approved standard. Second Edition. NCCLS document M31-A2 (ISBN 1- 56238-461-9). Wayne, PA: NCCLS.

16- CLSI. (2018) Performance standards for antimicrobial disk and dilution susceptibility tests for bacteria isolated from animals. Fourth edition. CLSI supplement VET08. Wayne, PA: CLSI.

17- Contreras A, Paape MJ,Miller RH. (1999) Prevalance of subclinical intramammary infection caused by Staphylococcus epidermidis in a commercial dairy goat herd. Small Ruminant Res. 31, 203-208.

18- Contreras A, Rodríguez JM. (2011) Mastitis: comparative etiology and epidemiology. J Mammary Gland Biol. 16, 339-356.

19- Contreras A, Sierra D, Sanchez A, Corrales JC, Marco JC, Paape MJ, Gonzalo C. (2007) Mastitis in small ruminants. Small Ruminant Res. 68, 145-153.

20- Cuccuru C, Melonmi M, Sala E, Scaccabarozzi L, Locatelli C, Moroni P, Bronzo V. (2011) Effects of intramammary infections on somatic cell score and milk yield in Sarda sheep. $N Z$ Vet $J$. 59, 128-131.

21- Dan $M$, Yehui $W$, Qingling $M$, Jun $Q$, Xingxing $Z$, Shuai $M$, Kuojun C, Jinsheng Z, Zibing C, Zaichao Z, Xuepeng C. (2019) Antimicrobial resistance, virulence gene profile and molecular typing of Staphylococcus aureus isolates from dairy cows in Xinjiang Province, northwest China. J Glob Antimicrob Resist. 16, 98-104.

22- Dinç G, Ata Z, Temelli S. (2012) Sığır mastitislerinden izole edilen Escherichia coli suşlarında genişlemiş spektrumlu beta-laktamaz aktivitesi ve antibiyotik dirençlilik profilinin incelenmesi. Ankara Üniv Vet Fak Derg. 59, 85-88.

23- Dore S, Liciardi M, Amatisteb S, Bergagnac S, Bolzonid G, Caligiuri V, Cerronee A, Farinaf G, Montagnag CO, Saletti MA, Scatassai ML, Sotgiuj G, Cannasa EA. (2016) Survey on small ruminant bacterial mastitis in Italy. Small Ruminant Res. 141, 91-93.

24- Erdoğdu M. (2019). Mastitisli sütlerden Klebsiella spp. izolasyonu ve antibiyotik dirençliliğinin belirlenmesi. Yüksek Lisans Tezi, ADÜ Sağlık Bilimleri Enstitüsü, Aydın.

25- Erganiş O, Kuyucuoğlu Y, Ok Ü. (1995) İnek ve koyun mastitislerine sebep olan koagulaz negatif ve pozitif stafilokokların biyotiplendirilmesi. Veterinarium. 6, 23-27.

26- EUCAST. (2019) Clinical Breakpoint Tables v. 9.0, valid from 2019-01-01.

27- Fotou K, Tzora A, Voidarou Ch, Alexopoulos A, Plessas E Avgeris I, Bezirtzoglou E, Akrida-Demertzi K, Demertzis PG. (2011) Isolation of microbial pathogens of subclinical mastitis from raw sheep's milk of Epirus (Greece) and their role in its hygiene. Anaerobe. 315-319.

28- Fragkou IA, Boscos CM, Fthenakis GC. (2014) Diagnosis of clinical or subclinical mastitis in ewes. Small Ruminant Res. 118 86-92.

29- Fthenakis GC, Arsenos G, Brozos C, Fragkou IA, Giadinis ND Giannenas I, Mavrogianni VS, Papadopoulos E, Valasi I. (2012) Health management of ewes during pregnancy. Anim Reprod Sci. 130, 198-212.

30- Fthenakis GC. (1998) Susceptibility to antibiotics of staphylococcal isolates from cases of ovine and bovine mastitis in Greece. Small Ruminant Res. 28, 9-13. 
31- Gelasakis AI, Mavrogianni VS, Petridis IG, Vasileiou NGC, Fthenakis GC. (2015) Mastitis in sheep-The last 10 years and the future of research. Vet Microbiol. 181, 136-146.

32- Gökdağ MO. (2017). Mastitis izolatı Stafilokok suşlarında vankomisin dirençliliğinin fenotipik ve genotipik olarak araştırılması. Yüksek Lisans Tezi, OMÜ Sağlık Bilimleri Enstitüsü, Samsun.

33- Gülcü HB, Ertaş HB. (2004) Elazığ yöresinde mezbahada kesilen ineklerde mastitisli meme loblarının bakteriyolojik incelenmesi. Turk J Vet Anim Sci. 28, 91-94.

34- Gülcü HB, Öngör H. (2002) Elazığ ilinde mezbahada kesilen koyun ve keçilerde meme loblarının mastitis yönünden bakteriyolojik incelenmesi. Vet Bil Derg. 18, 3-4.

35- Hadimli HH, Erganis O, Kav K, Sayin Z. (2010) Isolation of Arcanobacterium pyogenes from samples of sheep and cattle and identification by polimerase chain reaction. Kafkas Univ Vet Fak Derg. 16, 611-616.

36- İşnel Ceylan NB. (2009). Subklinik mastitisli keçilerde mikroorganizmaların izolasyonu ve antibiyotiklere duyarlılıklarının araştırılması. Yüksek Lisans Tezi, ADÜ Sağlık Bilimleri Enstitüsü, Aydın.

37- Jones JET, Watkins GH. (1998) Studies on mastitis in sheep at the Royal Veterinary College. Proceedings of the Sheep Veterinary Society, 22, 83-90.

38- Kern G, Traulsen I, Kemper N, Krieter J, (2013) Analysis of somatic cell counts and risk factors associated with occurrence of bacteria in ewes of different primary purposes. Live Sci. 157, 597-604.

39- Kesenkaş H. (1999). İzmir ili ve çevresinde seçilen pilot işletmelerde mastitisin belirlenmesi ve süt kalitesine etkisi üzerine bir araştırma. Doktora Tezi, EÜ Fen Bilimleri Enstitüsü, İzmir.

40- Koltaş S. (2016). Klinik ve subklinik mastitisli keçi sütlerinden bazı aerobik bakteri ve Mycoplasma spp. izolasyonu. Yüksek Lisans Tezi, Van YYÜ Sağlık Bilimleri Enstitüsü, Van.

41- Koop G, Rietman JF, Pieterse C. (2010) Staphylococcus aureus mastitis in Texel sheep associated with suckling twins. Vet Rec. 167, 868-869.

42- Kurt A. (2018). Sığır mastitis kökenli Streptokok izolatlarının bazı virülens özelliklerinin belirlenmesi. Yüksek Lisans Tezi, OMÜ Sağlık Bilimleri Enstitüsü, Samsun.

43- Li L, Feng W, Zhang Z, Xue H, Zhao X. (2015) Macrolidelincosamide-streptogramin resistance phenotypes and genotypes of coagulase-positive Staphylococcus aureus and coagulase-negative staphylococcal isolates from bovine mastitis. BMC Vet Res. 11, 168

44- Lollai SA, Ziccheddu M, Di Mauro C, Manunta D, Nudda A, Leori G. (2008) Profile and evolution of antimicrobial resistance of ovine mastitis pathogens (1995-2004). Small Ruminant Res. 74, 249-254.

45- Magiorakos AP, Srinivasan A, Carey RB, Carmeli Y, Falagas ME, Giske CG, Harbarth S, Hindler JF, Kahlmeter G, Olsson-Liljequist B, Paterson DL, Rice LB, Stelling J, Struelens MJ, Vatopoulos A, Weber JT, Monnet DL. (2012) Multidrug resistant, extensively drug-resistant and pandrug-resistant bacteria: an international expert proposal for interim standard definitions for acquired resistance. Clin Microbiol Infect. 18(3), 268-281.

46- Manser PA. (1986) Prevalence causes and laboratory diagnosis of subclinical mastitis in the goat. Vet Rec. 118, 552-554.

47- Marogna G, Rolesu S, Lollai S, Tola S, Leori G. (2010) Clinical findings in sheep farms affected by recurrent bacterial mastitis. Small Ruminant Res. 88, 119-125.

48- Mavrogianni VS, Cripps PJ, Fthenakis GC. (2007) Bacterial flo$\mathrm{ra}$ and risk of infection of the ovine teat duct and mammary gland throughout lactation. Prev Vet Med. 79, 163-173.

49- Mørk T, Waage S, Tollersrud S, Kvitle B, Sviland S. (2007) Clinical mastitis in ewes; bacteriology, epidemiology and clinical features. Acta Vet Scand. 49, 23-30.
50- Nebbia P, Robino P, Zoppi S, De Meneghi D. (2006) Detection and excretion pattern of Mycobacterium avium subspecies paratuberculosis in milk of asymptomatic sheep and goats by Nested-PCR. Small Ruminant Res. 66, 116-120.

51- Obaidat MM, Salman AEB, Amira A, Roess AA. (2018) High prevalence and antimicrobial resistance of mecA Staphylococcus aureus in dairy cattle, sheep, and goat bulk tank milk in Jordan. Trop Anim Health Prod. 50, 405-412.

52- Olechnowicz J, Jaśkowski JM. (2014) Mastitis in small ruminants. Med Weter. 70(2), 67-72.

53- Omaleki L, Barber SR, Allen JL, Browning GF. (2010) Mannheimia species associated with ovine mastitis. J Clin Microbiol. 48 3419-3422.

54- Onnasch $\mathrm{H}$, Healy AM, Brophy PO, Kinsella A, Doherty ML. (2002) A study of mastitis in sheep. Res Vet Sci. 72, 42.

55- Onni T, Sanna G, Larsen J, Tola S. (2011) Antimicrobial susceptibilities and population structure of Staphylococcus epidermidis associated with ovine mastitis. Vet Microbiol. 148, 45-50.

56- Özdemir FÖ. (2018). Subklinik mastitisli sığırlardan major patojenlerin izolasyonu ve antibiyotiklere duyarlılıklarının belirlenmesi. Yüksek Lisans Tezi, ADÜ Sağlık Bilimleri Enstitüsü, Aydın.

57- Petridis IG, Fthenakis GC. (2014) Administration of antibiotics to ewes at the beginning of the dry-period. J Dairy Res. 81 , 9-15.

58- Queiroga MC. (2017) Prevalence and aetiology of sheep mastitis in Alentejo region of Portugal. Small Ruminant Res. 153 123-130.

59- Quinn PJ, Markey BK, Leonard FC, FlizPatrick ES, Fanning S, Hartigan PJ. (2011) Veterinary microbiology and microbial disease. Second Edition. Oxford: Blackwell Science Ltd, p. 38-91.

60- Sabuncuoğlu N, Çoban Ö. (2006) Mastitis Ekonomisi. Atatürk Üniversitesi Vet Bil Derg. 1(1-2), 1-5.

61- Saratsis P, Leontides L, Tzora A, Alexopoulos C, Fthenakis GC. (1998) Incidence risk and aetiology of mammary abnormalities in dry ewes in 10 flocks in Southern Greece. Prev Vet Med. 37, 173-183.

62- Sasshofer A, Loibl A, Kessler O. (1987) Erkankungen be i Schaf und Ziege. 7. Euterentzündungen. Wien Tierarztl Mschr. 4, 125131.

63- Sur E. (2019). Subklinik mastitisli inek sütlerinden elde edilen Staphylococcus aureus izolatlarında bazı toksin genlerinin ve antibiyotik dirençliliğinin incelenmesi. Yüksek Lisans Tezi, ADÜ Sağlık Bilimleri Enstitüsü, Aydın.

64- Tel OY, Keskin O, Zonturlu AK, Arserim Kaya NB. (2009) Şanlıurfa yöresinde subklinik mastitislerin görülme oranı, aerobik bakteri izolasyonu ve duyarlı antibiyotiklerin belirlenmesi. F Ü Sağ Bil Vet Derg. 23 (2), 101-106.

65- Türkyılmaz S, Yıldız Ö, Oryaşın E, Kaynarca S, Bozdoğan B. (2010) Molecular identification of bacteria isolated from dairy herds with mastitis. Kafkas Univ Vet Fak Derg. 16 (6), 10251032.

66- Uçan N. (2014). Subklinik mastitisli keçilerdeki koagulaz negatif Stafilokokların saptanması ve antibiyotik dirençliliklerinin belirlenmesi. Yüksek Lisans Tezi, ADÜ Sağlık Bilimleri Enstitüsü, Aydın.

67- Winter P, Schlicher F, Bago Z, Schoder D, Egerbacher $M$, Baumgartner W, Wagner M. (2004) Clinical and histopathological aspects of naturally occurring mastitis caused by Listeria monocytogenes in cattle and ewes. J Vet Med. 51, 176-179.

68- Yağcı IP. (2008) Koyunlarda subklinik mastitis: etiyoloji, epidemiyoloji ve tanı yöntemleri. Kafkas Üniv Vet Fak Derg. 14(1), 117-122.

69- Zdragas A, Tsakos P, Kotzamanidis C, Anatoliotis K, Tsaknakis I. (2005) Outbreak of mastitis in ewes caused by Streptococcus agalactiae. J Hellenic Vet Med Soc. 56, 114-121. 